\title{
EFEKTIVITAS PENGGUNAAN CATATAN KEHAMILAN DIGITAL SEBAGAI MEDIA KOMUNIKASI DALAM PELAYANAN KEBIDANAN
}

\author{
Chanty Yunie Hartiningrum, Sinta Fitriani \\ STIKes Respati \\ (chanty.yunie@gmail.com, taniesa1571@gmail.com )
}

\begin{abstract}
ABSTRAK
Latar belakang : Media dalam promosi kesehatan merupakan salah satu upaya untuk mendukung keberhasilan proses pembelajaran sehingga lebih menarik perhatian dan materi yang disampaikan akan lebih mudah dipahami oleh sasaran saat mendapatkan pelayanan antenatal care. E-health merupakan penggunaan sarana elektronik atau teknologi digital untuk menyampaikan informasi, sumber daya, dan layanan yang terkait dengan kesehatan. Tujuan dari penelitian ini adalah mengetahui efektivitas penggunaan Catatan Kehamilan digital sebagai media komunikasi dalam pelayanan kebidanan di Tasikmalaya. Metodologi penelitian: Jenis penelitian yang digunakan adalah penelitian kuantitatif dengan metode quasi eksperimen. Populasi dalam penelitian ini adalah seluruh ibu hamil di wilayah Desa Cikunir. Teknik pengambilan sampling dilakukan dengan purposive sampling dimana terdapat 20 sampel yang memenuhi kriteria inklusi. Instrumen penelitian yang digunakan adalah kuesioner dan aplikasi kehamilan digital. Teknik analisis data menggunakan uji t karena data berdistribusi normal. Hasil penelitian : nilai signifikansi $0.000<0.05$ maka Ho ditolak dan Ha diterima sehingga dapat disimpulkan terdapat perbedaan rata rata pengetahuan sebelum dan sesudah menggunakan aplikasi catatan kehamilan (ada pengaruh penggunaan aplikasi catatan kehamilan terhadap peningkatan pengetahuan ibu hamil). Saran : Ibu hamil disarankan untuk meningkatkan upaya pencarian informasi kesehatan melalui berbagai cara salah satunya dengan memanfaatkan media berbasis android yang memiliki desain menarik dan praktis.
\end{abstract}

Kata kunci : Catatan kehamilan digital, media komunikasi, pelayanan kebidanan

\begin{abstract}
Background : Media in health promotion is one of the efforts to support the success of the learning process so that it attracts more attention and the material presented will be more easily understood by the target when getting antenatal care services. E-health is the use of electronic means or digital technology to deliver healthrelated information, resources and services. The purpose of this study was to determine the effectiveness of using digital pregnancy records as a communication medium in midwifery services in Tasikmalaya. Research methodology: The type of research used is quantitative research with quasi-experimental methods. The population in this study were all pregnant women in the Cikunir Village area. The sampling technique used was purposive sampling where there were 20 samples that met the inclusion criteria. The research instrument used was a questionnaire and a digital pregnancy application. The data analysis technique used the t test because the data were normally distributed. The results of the study: a significance value of $0.000<0.05$ then Ho is rejected and Ha is accepted so that it can be concluded that there is a difference in the average knowledge before and after using the application of pregnancy records (there is an effect of using the application of pregnancy records on increasing knowledge of pregnant women). Suggestion : Pregnant women are advised to increase their efforts to find health information through various ways, one of which is by utilizing android-based media that has attractive and practical designs.
\end{abstract}

Keywords: Digital pregnancy records, communication media, midwifery services 


\section{PENDAHULUAN}

Angka Kematian Ibu (AKI) di Indonesia masih cukup tinggi. Hal tersebut menilik capaian penurunan AKI di beberapa negara Asean. AKI di negara-negara Asean sudah menempati posisi 40-60 per 100 ribu kelahiran hidup. Sedangkan di Indonesia berdasarkan Survei Penduduk Antar Sensus (SUPAS) 2015 masih menempati posisi 305 per 100 ribu kelahiran hidup. Hal ini berbeda jauh dengan Singapura yang berada 2-3 AKI per 100 ribu kelahiran. Sementara itu, data capaian kinerja Kemenkes RI tahun 20152017 menunjukkan telah terjadi penurunan jumlah kasus kematian ibu. Jika di tahun 2015 AKI mencapai 4.999 kasus maka di tahun 2016 sedikit mengalami penurunan menjadi 4.912 kasus dan di tahun 2017 mengalami penurunan tajam menjadi sebanyak 1.712 kasus AKI. (Kemenkes RI, 2018)

Pelayanan antenatal merupakan upaya untuk menjaga kesehatan ibu pada masa kehamilan, sekaligus upaya menurunkan angka kesakitan dan angka kematian ibu. Antenatal merupakan perawatan atau asuhan yang diberikan kepada ibu hamil sebelum kelahiran, yang berguna untuk memfasilitasi hasil yang sehat dan positif bagi ibu hamil maupun bayinya dengan jalan menegakkan kepercayaan dengan ibu, mendeteksi komplikasi yang dapat mengancam jiwa, mempersiapkan kelahiran dan memberikan pendidikan kesehatan (Anonim, 2011)

Antenatal care yang memadai oleh penyedia layanan kesehatan profesional telah terbukti tidak hanya untuk mengurangi morbiditas dan kematian ibu, janin dan bayi tetapi juga untuk meningkatkan status kesehatan dan perilaku pengasuhan ibu setelah anak lahir. Ketidakpuasan dapat menjadi faktor utama dalam penggunaan fasilitas layanan antenatal, kepuasan dapat meningkatkan frekuensi kunjungan dan hubungan baik dengan penyedia layanan (Galle A et al, 2015).

Hal ini menunjukkan bahwa tugas bidan dalam memberikan pelayanan antenatal dapat menurunkan kehamilan dengan berisiko tinggi dan menciptakan komunikasi yang lebih baik selama memberikan layanan pemeriksaan kehamilan (Galle A et al, 2015).

Salah satu kegiatan dalam pelayanan ante natal care adalah pendidikan kesehatan saat antenatal yang dianggap penting untuk mempengaruhi perilaku perempuan . Hal ini penting mengingat bahwa sumber informasi utama yang digunakan oleh wanita selama kehamilan untuk memenuhi kebutuhan informasi mereka tentang kehamilan, kelahiran dan masa postpartum. Sebuah studi menemukan bahwa $70 \%$ dari wanita hamil melakukan "diskusi dengan bidan" sebagai sumber informasi, kurang dari setengah dari perempuan menggunakan internet untuk mengakses informasi, dan hanya 2,4\% informasi grup (Yeoh PL, 2015)

Beberapa faktor yang mempengaruhi pendidikan kesehatan adalah materi atau pesan yang disampaikan, alat bantu atau alat 
peraga yang digunakan, metode penyampaian materi serta pendidik atau petugas yang melakukan pendidikan kesehatan. Media dalam promosi kesehatan merupakan salah satu upaya untuk mendukung keberhasilan proses pembelajaran sehingga lebih menarik perhatian dan materi yang disampaikan akan lebih mudah dipahami oleh peserta. Melalui promosi kesehatan menggunakan metode dan media situasi pembelajaran lebih menyenangkan, kreatif dan tidak membosankan (Fitriani, 2011).

Menurut Soekidjo tahun 2011 media promosi kesehatan adalah semua sarana atau upaya untuk menampilkan pesan atau informasi yang tersedia yang ingin disampaikan oleh komunikator, baik itu melalui media cetak, elektronik (TV, radio, komputer, dan sebagainya) dan media luar ruang, sehingga sasaran dapat meningkatkan pengetahuannya yang akhirnya diharapkan adanya perubahan perilaku ke arah positif atau lebih baik. Salah satu media yang efektif berpengaruh terhadap pengetahuan sasaran adalah penggunaan media elektronik berbasis internet.

E-health merupakan penggunaan sarana elektronik atau teknologi digital untuk menyampaikan informasi, sumber daya, dan layanan yang terkait dengan kesehatan. Hal-hal yang termasuk bagian dari e-health, sebagai berikut: rekam medik, mobile health (aplikasi, teknologi, alat kesehatan dengan teknologi mobile), telemedis (misalnya pasien dapat berkonsultasi dengan petugas kesehatan melalui komputer, tablet, atau ponsel), dan elearning kesehatan (Ariyanti, 2017).

Tujuan dari penelitian ini adalah mengetahui efektivitas penggunaan Catatan Kehamilan digital sebagai media komunikasi dalam pelayanan kebidanan di Tasikmalaya. Berdasarkan data diatas penulis tertarik untuk melakukan penelitian dengan judul Efektivitas Penggunaan Catatan Kehamilan Digital Sebagai Media Komunikasi Dalam Pelayanan Kebidanan.

\section{METODE PENELITIAN}

Jenis penelitian yang digunakan adalah penelitian kuantitatif dengan metode quasi eksperimen. Populasi dalam penelitian ini adalah seluruh ibu hamil di wilayah Desa Cikunir. Teknik pengambilan sampling dilakukan dengan purposive sampling dimana terdapat 20 sampel yang memenuhi kriteria inklusi. Instrumen penelitian yang digunakan adalah kuesioner dan aplikasi kehamilan digital. Teknik pengambilan data dilakukan secara langsung. Responden mengisi kuesioner pretest kemudian bersama sama menggunakan aplikasi kehamilan digital dengan dipandu oleh peneliti. Setelah menggunakan aplikasi, responden kemudian mengisi kuesioner post test. Teknik analisis data menggunakan uji $\mathrm{t}$ karena data berdistribusi normal. 


\section{HASIL DAN PEMBAHASAN}

Tabel 1. Karakteristik responden

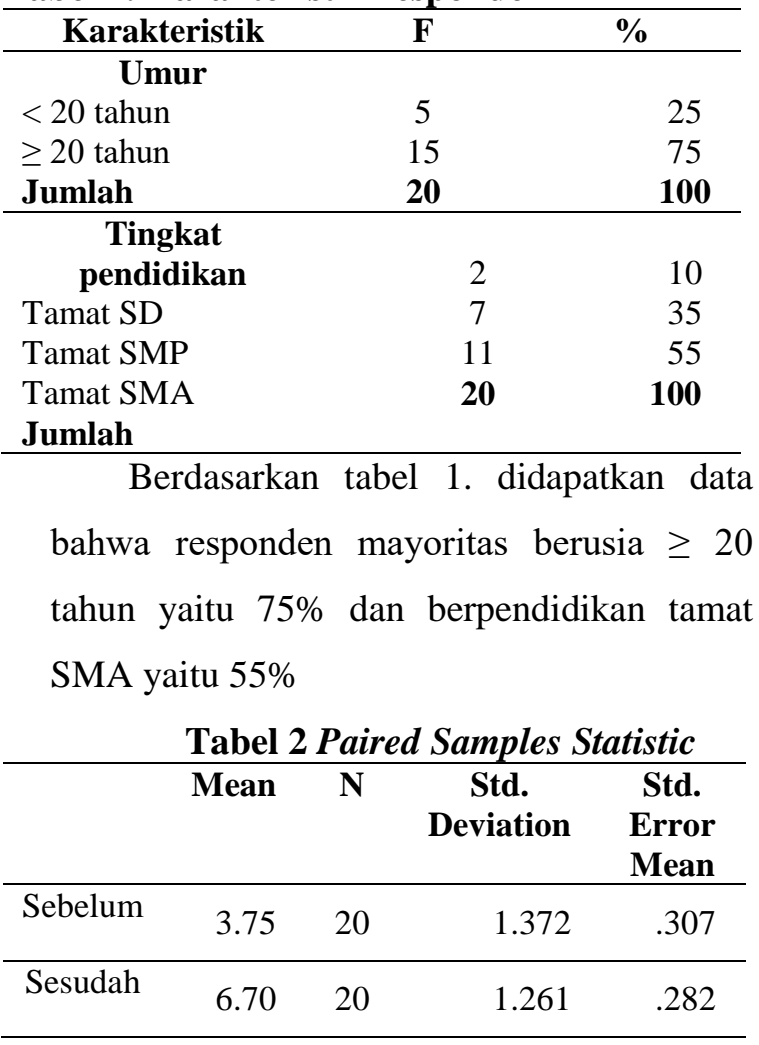

Berdasarkan tabel 2. diatas didapatkan bahwa nilai rata rata sebelum menggunakan aplikasi catatan kehamilan digital yaitu 3.75 dan rata rata sesudah intervensi adalah 6.70. Untuk nilai standar deviasi sebelum adalah 1.372 dan sesudah 1.261. Sedangkan nilai standar error sebelum intervensi adalah 0.307 dan sesudah 0.282

Tabel 3 Paired Samples Correlation

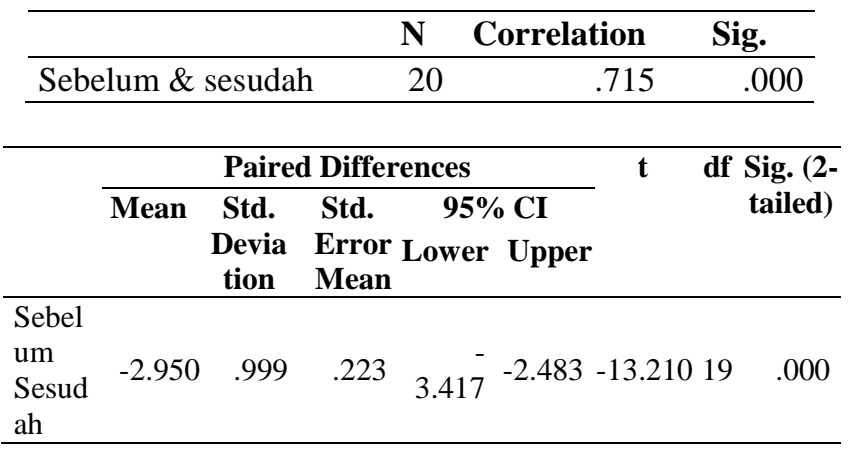

Berdasarkan tabel 3 didapatkan nilai signifikansi $0.000<0.05$ maka Ho ditolak dan Ha diterima sehingga dapat disimpulkan terdapat perbedaan rata rata pengetahuan sebelum dan sesudah menggunakan aplikasi catatan kehamilan (ada pengaruh penggunaan aplikasi catatan kehamilan terhadap peningkatan pengetahuan ibu hamil).

Pendidikan kesehatan yang dilakukan pada saat melaksanakan pelayanan antenatal care dapat dilakukan melalui komunikasi konseling dimana komunikasi konseling kebidanan adalah gambaran terjadinya interaksi antara bidan dengan klien dalam upaya pemenuhan kebutuhan klien; sebagai faktor pendukung pelayanan profesional oleh bidan. Kemampuan komunikasi dalam pelayan kebidanan akan mendasari upaya pemecahan masalah klien, dan mempermudah dalam memberi bantuan kepada klien. Komunikasi kebidanan tidak hanya mendasari pelayanan kebidanan individu, tetapi juga pelayanan keluarga, kelompok atau masyarakat.

Untuk mempermudah penerimaan pesan sasaran media memiliki peranan penting dimana menurut Soekidjo tahun 2010 media promosi kesehatan adalah semua sarana atau upaya untuk menampilkan pesan atau informasi yang tersedia yang ingin disampaikan oleh komunikator, baik itu melalui media cetak, elektronik (TV, radio, komputer, dan sebagainya) dan media luar ruang, sehingga sasaran dapat 
meningkatkan pengetahuannya yang akhirnya diharapkan adanya perubahan perilaku ke arah positif atau lebih baik.

Salah satu media yang berpengaruh adalah E-health (electronic health) merupakan penggunaan sarana elektronik atau teknologi digital untuk menyampaikan informasi, sumber daya, dan layanan yang terkait dengan kesehatan. Penelitian yang dilakukan oleh Lupton (2017) yang berjudul: "It Just Gives Me a Bit of Peace of Mind: Australian Women's Use of Digital Media for Pregnancy and Early Motherhood". Hasil penelitian menunjukkan bahwa media digital sangatlah penting bagi ibu hamil maupun ibu muda. Informan menggunakan aplikasi, media sosial, dan forum diskusi online untuk mencari informasi mengenai kehamilan, perkembangan anak, dan perawatan bayi.

Penelitian mengenai pemanfaatan $\mathrm{mH}$ sebagai media promosi kesehatan dilakukan oleh Jabbour (2013) dan Lupton (2012). Kedua penelitian tersebut bertujuan untuk mengetahui promosi kesehatan dengan menggunakan mobile health. Jabbour (2013) melakukan penelitian mengenai aplikasi mhealth school yang dikembangkan oleh sekolah di Libanon yang berjudul M-health, New Prospect for School Health Educations Through Mobile Technologies at Lebanese School.

Menurut dibi dan Sasan (2015), salah satu media mHealth adalah smartphone, dimana app yang merupakan aplikasi yang menjadi sarana pemberian informasi di SSC merupakan salah satu aplikasi yang bisa digunakan pada smartphone. Pengguna smartphone di Indonesia mencapai 66,3\% (Kominfo RI, 2017). Hal ini menyebabkan SSC sangat potensial digunakan sebagai media pendidikan kesehatan.

Menurut Pine dan Fletcher (2015), menyesuaikan isi dan jumlah proporsi edukasi kesehatan yang diberikan dengan bahasa dan budaya penerima dapat mempermudah dalam penyampaian informasi. Berdasarkan hal ini peneliti berusaha memilih kata yang sederhana dan lebih mudah dipahami serta menambahkan kalimat ajakan dalam proses penyampaiankan pesan.

\section{KESIMPULAN DAN SARAN}

Kesimpulan dalam penelitian ini adalah terdapat pengaruh penggunaan aplikasi catatan kehamilan digital terhadap peningkatan pengetahuan ibu hamil di Tasikmalaya. Ibu hamil disarankan untuk meningkatkan upaya pencarian informasi kesehatan melalui berbagai cara salah satunya dengan memanfaatkan media berbasis android yang memiliki desain menarik dan praktis.

\section{DAFTAR PUSTAKA}

Adibi, \& Sasan. (2015). Mobile Health A Technology Road Map Spanyol: Springer Series in Bio/Neuroinformatics.

Anonim. Inilah Manfaat Pemeriksaan Kehamilan. 2016. 
http://doktersehat.com/inilah-manfaat pemeriksaan-kehamilan/.

Digital Health.( 2018). Critical and CrossDisciplinary Perspective London. New York: Routledge.

Early, J., Gonzalez, C., Gordon-Dseagu, V., \& Robles-Calderon, L. (2019). Use of Mobile Health (mHealth) Technologies and Interventions Among Community

Fitriani, Sinta. 2011. Promosi Kesehatan. Yogyakarta .Graha Ilmu.

Galle A, Van Parys A, Roelens K, Keygnaert (2015).Expectations and satisfaction with antenatal care among pregnant women with a focus on vulnerable groups: a descriptive study in ghent. BMC Women's Health.

Health Workers Globally: A Scoping Review. Health Promotion Practice, 20 (6), 805-817.

https://doi.org/10.1177/15248399198 55391

Hilty, Donald and Stevan Chan. (2018). Human Behavior with Mobile Health: Smartphone / Devices, Apps and Cognition, 4(2), 36-47. https://doi.org/10.17140/PCSOJ-4141.

Ismael, A.G., Jabar, E.K.(2013). Effective sistem for pregnant women using mobile International Journal of Computer Applications. Vol $64 . \quad$ (11). http://research.ijcaonline.org/volume64/ number11/pxc3885547.pdf

It Just Gives Me a Bit of Peace of Mind . (2017). Australian Women's Use of Digital Media for Pregnancy and Early Motherhood: MDPI Societies, (September). https://doi.org/10.3390/soc7030025.

Jabbour, Khayrazad Kari. 2013. M-Health,New Prospect For School Health Education Through Mobile Technologies at Lebanese School. Acta Didactica Napocensia, Vol.6 No.2.

Kemenkes RI. Infodatin Pusat data dan informasi Kemenkes RI. 2018.
Kumar, et.al. 2013. Mobile Health Technology Evaluation. Journal HHS Public Acces (https://doi.10.1016/j.amepre.2013.03.0 17).

Lupton, D., \& Maslen, S. (2019). How Women Use Digital Technologies for Health : Qualitative Interview and Focus Group Study. Journal of Medical Intenet Research, (January). https://doi.org/10.2196/11481.

M-health and Health Promotion. (2012. The Digital Cyborg and Surveillance Society. Journal Social Theory Health Vol. 10, 3, 229-24

Notoatmodjo, S. (2014). Promosi Kesehatan dan Perilaku Kesehatan. Jakarta: Rineka Cipta.

Nundy, S., Dick, J., Solomon, M. C., \& Peek, M. E. (2012). Developing a Behavioral Model for Mobile Phone - Based Diabetes Interventions. Patient Education and Counseling. XC: $125-32$.

Sri Ariyanti, 2Kautsarina.Kajian TeknoEkonomi pada Telehealth di IndonesiaTechno-Economic Study on Telehealth in Indonesia.Buletin Pos dan Telekomunikasi Vol. 15 No.1 (2017): 43-54

Tang, Y., \& Hew, K. F., (2017). Is Mobile Instant Messaging (MIM) Useful in Education? Examining Its Technological, Pedagogical, and Social Affordances. Educational Research Review.

Yeoh PL, Hornetz K, Ahmad Shauki NI, Dahlui M (2015). Assessing the extent of adherence to the recommended antenatal care content in Malaysia: Room for improvement. PloS One.

Yeoh PL, Hornetz K, Dahlui M (2015), Antenatal care unilisation and content between Low Risk and High Risk pregnant women. PloS One. 